\title{
Insuring the Low-Income Market: Challenges and Solutions for Commercial Insurers
}

\section{Craig Churchill}

International Labour Organization, Social Finance Programme, Employment Sector, 4, rte des Morillons, Geneva 22 CH 1211, Switzerland.

E-mail: churchill@ilo.org

In many developing countries, commercial insurers are beginning to become interested in serving the low-income market by providing microinsurance. To do so, they have to overcome both operational and regulatory obstacles. Ironically, certain regulations actually give commercial insurers an advantage in serving the low-income market, by restricting competition from specialized microinsurance companies. However, this opportunity is unlikely to last indefinitely. Commercial insurers that are keen to reach out to new markets, such as the huge volume of low-income people in many countries, would be wise to move quickly to overcome key operational issues. In particular, insurers need to recognize that microinsurance is not just existing products with smaller insured sums, but rather requires a significantly different approach from conventional insurance. Key starting points include (a) improving the insurer's familiarity with the preferences and behavior of poor persons, and (b) educating the market about insurance to create low-income consumers.

The Geneva Papers (2007) 32, 401-412. doi:10.1057/palgrave.gpp.2510132

Keywords: microinsurance; insurance regulation and supervision; inclusive insurance markets

\section{Introduction}

As described in a recent co-publication ${ }^{1}$ by the International Labour Organization (ILO) and Munich Re Foundation, low-income persons live in risky environments, vulnerable to numerous perils. The poor are more vulnerable to risks than the rest of the population, and they are the least able to cope when a crisis does occur. Furthermore, poverty and vulnerability reinforce each other in an escalating downward spiral. Not only does exposure to risks result in financial losses, but poor households also suffer from the uncertainty about whether and when a loss might occur. Because of this apprehension, the poor are less likely to take advantage of income-generating opportunities that might reduce poverty.

Microinsurance is a reasonably new intervention to address this problem, or at least the term "microinsurance" has only been around since the late 1990s. Microinsurance emerged on the coat tails of the burgeoning microfinance industry, which has received significant attention in recent years: 2005 was the United Nations' International

\footnotetext{
${ }^{1}$ This article draws from Churchill (2006a), especially Botero et al. (2006), Churchill (2006b), and Wiedmaier-Pfister and Chatterjee (2006).
} 
Year of Microcredit. In 2006, one of the innovators and key spokespersons for microfinance, Mohammed Yunus, and the organization that he founded, the Grameen Bank in Bangladesh, received the Nobel Peace Prize. In this context, microinsurance is also beginning to get some attention. After providing credit, and later savings, to poor entrepreneurs and low-income households, microfinance institutions (MFIs) started experimenting with insurance as well, sometimes on their own and sometimes in collaboration with insurance companies.

But in truth, microinsurance is not really new. Some of today's large insurance companies began in the $1800 \mathrm{~s}$ as mutual protection schemes among low-income workers. In the early 1900s, many insurers built their business by selling "industrial insurance" at factory gates. At that time, insurance was seen as a financial service for the poor, since wealthy people essentially self-insured. Over the years, however, this perception has reversed - many poor people today think insurance is only for the wealthy. Indeed, microinsurance can be described as a "back to basics" campaign for the insurance industry, to protect vulnerable people through the solidarity of risk pooling.

This article begins by defining microinsurance and explaining its recent emergence. Next, the article lists the reasons why commercial insurers have not served the lowincome market in recent years. Then it describes key strategies that commercial insurers need to consider when serving this market. Lastly, this article concludes with a summary of the main regulatory issues that impede the expansion of microinsurance, some of which give commercial insurers interested in going "down market" an advantage over specialized microinsurance organizations.

\section{What is microinsurance?}

Microinsurance is the protection of low-income people against specific perils in exchange for regular premium payments proportionate to the likelihood and cost of the risk involved. This definition is essentially the same as one might use for regular insurance except for the clearly prescribed target market: low-income people. However, as this article will demonstrate, those three words make a big difference.

How poor do people have to be for their insurance protection to be considered micro? The answer varies by country. Generally, microinsurance is for persons ignored by mainstream commercial and social insurance schemes. The ILO is particularly interested in the provision of cover to persons working in the informal economy. Since it is easier to offer insurance to persons in the formal economy with a predictable income than to cover informal economy workers with irregular cash flows, the latter represent the microinsurance frontier.

Microinsurance can cover a variety of different risks, including illnesses, accidental injuries, death and property loss - any risk that is insurable as long as the product is affordable and accessible for low-income households. Microinsurance can be offered as a single risk product or several covers can be bundled together into a composite product, perhaps even underwritten by different risk carriers.

Microinsurance does not refer to the size of the risk carrier, although some providers are small and even informal. There are, however, examples of very large companies that offer microinsurance, such AIG Uganda, Delta Life in Bangladesh, 
Zurich in Bolivia, and all insurance companies in India, which are required to serve the "rural and social sectors" by the regulatory authorities.

Insurance can be delivered to low-income households through a variety of channels. Microinsurance risk carriers include small community-based schemes, mutuals and cooperatives, as well as joint stock companies and government-owned insurers. To reach poor households, risk carriers often partner with delivery channels that already have financial transactions with the low-income market. The most common arrangement is with MFIs that provide credit and perhaps savings services, and therefore microinsurance essentially becomes bancassurance. However, delivery channels can also include cooperatives, community organizations, small business associations, trade unions and even retail companies that cater to the low-income market.

In summary, microinsurance is not a specific product or product line. It is also not limited to a specific provider type. Microinsurance is the provision of cover to a specific market segment, that is, low-income persons.

\section{The emergence of microinsurance}

Microinsurance is primarily a phenomenon in developing countries. This is partly because insurance penetration is low and government social protection schemes only cover a small minority of citizens. Consequently, microinsurance has emerged to fill the gap from three parallel entry points. First, to cope with risks, many low-income persons form their own mutual benefit associations, burial societies and the like. Some of these unregulated insurance schemes have grown quite large, posing a dilemma for regulators (see Box 1). Second, some development agencies, like the ILO, have encouraged persons excluded from commercial and social insurance schemes to create risk-pooling mechanisms. The ultimate intention of many of these donor-led efforts is to link them to government support in order to facilitate a redistribution of resources from the rich to the poor. Third, with encouragement from MFIs, some insurers see the vast number of low-income persons in developing countries as a new market opportunity.

This "new market" perspective has been best articulated by C.K. Prahalad in his book Fortune at the Bottom of the Pyramid. Prahalad identifies the more than four billion persons living on less than US\$2 per day as a market opportunity if the providers of products and services, including multinational corporations, innovate new business models and create low-income consumers. ${ }^{2}$

Prahalad's analysis draws examples from various industries, including construction, financial services, consumer goods and healthcare. Based on case studies of successful innovations, Prahalad identifies common principles to be considered when innovating for the bottom of the pyramid (BOP). Even though he does not analyse insurance case studies, Prahalad's principles are remarkably applicable to the provision of microinsurance.

\footnotetext{
${ }^{2}$ Prahalad (2005)
} 
Box 1 Informal insurance in South Africa

In South Africa, a number of schemes offer products that closely resemble life insurance. In the informal sector, there are an estimated eight million members of informal burial societies contributing in excess of US\$1 billion per annum in "premiums" towards coverage for the risk of death. Some of these schemes are quite large. The Great North Burial Society, a registered Friendly Society, has more than 20,000 lives covered, but is unable to access reinsurance as it is not a licensed insurer.

Consequently, a catastrophe would pose a serious threat to the solvency of such a scheme. In addition, the growth of informal schemes can pose a threat to sustainability. For example, when burial societies become larger, the efficacy of the member-governance system is undermined and a separation is required between management and ownership. At this point, the burial society also accumulates substantial assets, which increases the risk of fraud or theft to a degree that member governance cannot control.

If regulators intervene and force the formalization of informal insurance schemes, they could be trying to force a round peg into a square hole, since insurance regulations were not designed to accommodate this type of organization. Should they shut down informal schemes since they are essentially illegal? If informal schemes are allowed to operate, how should they determine the threshold that mandates regulatory intervention? Or is there some middle ground that could expand access to insurance with some degree of consumer protection?

Source: Adapted from Genesis Analytics (2005).

In particular, when serving the BOP, the basis for returns on investment is volume. Even if the per unit profit is minuscule, when it is multiplied across a huge number of sales, the return can become attractive. This attribute is a perfect fit for insurance and the Law of Large Numbers, whereby actual claims experience should run much closer to the projected claims when the risk pool is larger. When projections can be estimated with a high degree of confidence, then the product pricing does not have to include a large margin for error, making it more affordable to the poor. Prahalad also makes a strong case for: (a) utilizing technology to enhance the efficiency of managing large volumes of small transactions; and (b) making significant investments in educating the market in order to create a demand - both of which are essential for the successful uptake of insurance by the poor.

As Prahalad's thinking filters through the insurance industry, many commercial companies are beginning to look at the low-income market a bit differently, especially when the results from vanguard insurers show that it is possible to provide microinsurance profitably. Yet to serve this market, insurers have to think differently - about customers' needs, product design, delivery systems and business models.

\section{Why do commercial insurers not serve the poor?}

To understand how to develop new business models for microinsurance, first it is necessary to assess why mainstream approaches do not reach the poor. Although the insurance industry is beginning to notice the vast under-served market of low-income households, insurers must overcome numerous obstacles if they are to offer quality microinsurance products.

One of the primary stumbling blocks is the transaction cost associated with managing large volumes of small policies. In serving the poor, insurers incur 
significant expenses in marketing to a clientele that may be unfamiliar with insurance, collecting premiums from persons who may not have bank accounts, and assessing and paying out small claims. As a percentage of the premiums, these costs are relatively higher for smaller policies.

A related problem is the distribution of insurance to the low-income market. The system of brokers, agents and direct sales used by commercial insurers is generally appropriate for corporate customers and high-value individual customers, but does not reach the poor.

The products generally available from insurers are not designed to meet the specific characteristics of the low-income market, particularly the irregular cash flows of households with breadwinners in the informal economy. Other key product design challenges include inappropriate insured amounts, complex exclusions and indecipherable legal policy language, all of which conspire against effectively serving the poor.

It is generally assumed that low-income men and women are more vulnerable to risks than the not-so-poor; however, most insurers do not have data to accurately interpret the vulnerabilities of the poor. To address such a problem, insurers may build in a hefty margin for error and then make adjustments once the claims experience starts rolling in. However, if insurers build in a cushion on top of the high administrative costs required to serve the low-income market, premiums may not be affordable.

Insurers do not have the right mechanisms to control certain insurance risks, such as adverse selection and fraud, among the low-income market. For example, the claims documentation requirements and the verification techniques that are used to ensure that someone with a US\$100,000 life policy is not defrauding the insurer are inappropriate for a US\$500 policy.

Lastly, a major challenge in extending insurance to the poor is educating the market and overcoming its bias against insurance. Many poor persons are sceptical about paying premiums for an intangible product with future benefits that may never be claimed - and they are often not too trusting of insurance companies. Creating awareness about the value of insurance is time-consuming and costly.

This bias goes in both directions. The people who work for insurance companies are usually unfamiliar with the needs and concerns of the poor. They assume that the poor cannot afford insurance. Additionally, the culture and incentives in insurance companies reward and encourage salespersons to focus on larger policies, more profitable clients and discourage staff from the ridiculous idea of selling insurance to the poor.

\section{How can commercial insurers serve the poor?}

By identifying these challenges, it is possible to design strategies and approaches by which commercial insurers can overcome them to actually provide valuable insurance coverage to poor persons. The first step is to understand the market, which is not so easy given the significant social and economic differences between persons working for insurance companies and those working in the informal economy. 
Any marketing course begins with the notion that a product must benefit a customer or fulfil a particular customer need. Pretty straightforward. But in microinsurance, it is important that commercial insurers recognize that they probably do not know very much about the target market, and therefore they must have an open mind about how to solve the needs of these customers.

Consequently, insurers have to make a special effort to understand the low-income market, for example, through surveys, focus groups and so on. Insurance professionals who have spent time interacting with poor persons invariably come away with two pertinent observations: (1) these people definitely need insurance as a tool to help them manage risks; and (2) a different approach to product design and delivery is required to serve this market.

Key differences between microinsurance and commercial insurance are not just in the products themselves, but also in how they are made accessible to poor persons. As summarized in Table 1, microinsurance products are not scaled down versions of existing products. They should be as simple as possible, with a minimum of exclusions or restrictions. The product and its related processes must be simple enough so that illiterate people can understand them.

After insurers educate themselves, then they need to think about educating the prospective market. The demand for microinsurance requires some coaxing. There is certainly a need to develop new techniques to convey the usefulness of insurance to an illiterate or uneducated market. For example, some organizations rely on unconventional communication methods, such as street theatre and soap opera-style videos. Efforts to sell insurance to the poor will be more effective if they are preceded by a financial education campaign that helps poor persons understand how insurance works, what it can and cannot accomplish, and how it complements other financial services.

Table 1 Illustrative distinctions between commercial and micro insurance

\begin{tabular}{|c|c|}
\hline Commercial insurance & Microinsurance \\
\hline $\begin{array}{l}\text { Premium collected mostly from deductions } \\
\text { in bank account }\end{array}$ & $\begin{array}{l}\text { Premium often collected in cash or associated } \\
\text { with another financial transaction; should be } \\
\text { designed to accommodate customers' irregular } \\
\text { cash flows, which may mean frequent payments }\end{array}$ \\
\hline $\begin{array}{l}\text { Agents and brokers are primarily responsible } \\
\text { for sales }\end{array}$ & $\begin{array}{l}\text { Agents may manage the entire customer } \\
\text { relationship, perhaps including premium collection }\end{array}$ \\
\hline Targeted at wealthy or middle class clients & Targeted at low-income persons \\
\hline Market is largely familiar with insurance & Market is largely unfamiliar with insurance \\
\hline $\begin{array}{l}\text { Screening requirements may include a } \\
\text { medical examination }\end{array}$ & $\begin{array}{l}\text { If there are any screening requirements, they } \\
\text { would be limited to a declaration of good health }\end{array}$ \\
\hline Sold by licensed intermediaries & Often sold by unlicensed intermediaries \\
\hline Large sums insured & Small sums insured \\
\hline Priced based on age/specific risk & Community or group pricing \\
\hline Limited eligibility with standard exclusions & Broadly inclusive, with few if any exclusions \\
\hline Complex policy document & Simple, easy to understand policy document \\
\hline
\end{tabular}

Adapted from McCord and Churchill (2005). 
Communication and education efforts have to move beyond sales to create an insurance culture. In many developed countries, it took generations before people commonly turned to insurance to address their risk-management needs. Microinsurance providers can help build the culture of insurance if they serve their clients' needs in a fair and equitable way.

Microinsurance products that respond appropriately to potential policyholders' needs and demands will help to generate an insurance culture. The key strategy to achieve this goal is to involve policyholders (or prospective clients) in the process of making hard choices between benefits and price. The poor cannot afford comprehensive coverage, so which benefits are they most willing to pay for, and how much are they willing to pay? Tools that can enable clients to see the trade-offs and voice their preferences will go a long way towards appropriate product design.

Paying a claim - delivering on a promise - is arguably the most important opportunity to reinforce the value of insurance. Yet insurers are notorious for being quick to take the policyholder's money and slow to pay it out. Microinsurance has to prove otherwise. The best marketing opportunity for an insurer, the best way to change the opinion of a lukewarm and sceptical market, the best way to demonstrate its trustworthiness, is to pay claims. Ironically, to increase the acceptance of insurance as an effective risk-management tool among the poor, insurers should actually encourage claims! At least, insurers should take great pains to avoid rejecting claims, for example, by keeping the product simple, making sure policyholders are crystal clear about what is and is not covered, and requiring only the most basic claims documentation, which is easy to access.

There is no room for fat in a microinsurance budget. By keeping the product simple, it may be possible to hire less expensive staff members, ideally people who come from the local communities. Where possible, insurers should rely on existing groupings to conduct bulk transactions. One way to earn the trust of the market and maximize efficiencies is to collaborate with community organizations. Well-respected organizations and community leaders can enhance the credibility of insurance (or of insurers). If the local organization already engages in some sort of financial transaction with the target market, then efficiencies could be generated by "piggybacking" premium collection onto a loan, savings or money transfer service.

Great expectations are placed on the potential of technology to enhance efficiency. Technology can improve the microinsurance business because of the informationprocessing nature of the sector. Even before the birth of the computer, large insurance companies drove the development of sorting, tabulating and calculating machines to improve efficiency. Today, these capabilities are available to small insurers as well. Microinsurers big and small must take advantage of ways of improving efficiency, through the use of smartcards, mobile phones, the Internet and wireless communications, among others.

If insurers are serious about serving the low-income market, they are not likely to get too far if it is just a piece of someone's responsibilities. To succeed in an insurance company, microinsurance needs dedicated human resources, as well as some space to experiment and innovate, to do things differently than the insurer has done them in the 
past. Different sets of incentives and targets should be considered for microinsurance staff members.

To provide good value to customers, insurers must take a long-term perspective and assume that real returns will only come several years down the line. Efforts to generate quick returns may backfire by reinforcing the market's negative perception of insurers. Instead, the focus should be on maximizing customer loyalty under the expectation that today's low-income household may be in tomorrow's middle class, demanding larger sums assured and additional covers.

\section{Regulatory issues for commercial insurers going "down market"}

Besides the operational challenges of serving the low-income market, commercial insurers in some jurisdictions also face regulatory challenges. This section summarizes the main regulatory issues that commercial insurers may encounter when providing microinsurance, some of which actually create significant advantages for them. This section considers the regulatory barriers that limit the creation of microinsurance companies as well as those that impede the proliferation of microinsurance products.

\section{Regulatory barriers for creating formal microinsurance institutions}

If regulators treat microinsurance in the same way as commercial life and non-life insurance, it could actually discourage its development. While it is certainly easier for the insurance supervisor to treat all risk carriers alike, it will not lead to more inclusive insurance markets. If regulators are serious about expanding insurance markets, then they need to find ways of involving different types of risk carriers and delivery channels that are able to provide different services to different market segments.

One would expect that an insurer that was primarily committed to serving the lowincome market would be more effective at doing so than a company that only dappled in microinsurance. In practice, however, many regulations conspire against the emergence of specialized microinsurance organizations in favor of commercial insurers. Consequently, commercial insurers that are keen to serve the low-income market actually benefit from many regulations that stymie the development of microinsurance in general.

For example, high capital requirements can impede the entry of specialized microinsurance institutions since amassing the volume of small policies required to generate a return on such an investment could take years. High capital requirements designed to protect the financial system seem inappropriate for such small contracts like an elephant of capital to protect an anthill of policies. Still, where such regulation exists, commercial insurers can actually benefit, since they already have a license and the required capital, and the regulation limits the competition to serve for the lowincome market.

Similarly, commercial insurers have an advantage over specialized microinsurers because of regulations that specify the requirements for key management. Highly qualified insurance managers are unlikely to opt to lead a microinsurance organization, which generally has a low salary profile and few career opportunities, when they could work for a commercial insurer. 
Complex reporting requirements can make the cost of management and administration prohibitively expensive for small microinsurance operators. If reporting and disclosure requirements, originally designed for large insurance companies with complex structures, are imposed on specialized microinsurers with simple procedures, cost ratios will rise.

Regulators need to identify where entry barriers can be lowered to promote microinsurance. Certainly, they are justified in not licensing entities with weak management and low capital. However, it is questionable to deny licences to microinsurance schemes due to requirements that are neither relevant nor appropriate for the types of services that they offer. This is particularly true for mutuals and friendly societies, where capital requirements should be lower since risk is borne by the membership.

In jurisdictions where such regulations do impede the creation of specialized microinsurance companies, these obstacles are unlikely to remain in place indefinitely. The International Association of Insurance Supervisors (IAIS) is looking carefully at the issue of microinsurance and is likely to conclude that some accommodations are required to promote more inclusive insurance markets, including different institutional options. Where policymakers embrace this perspective, it could open the door to more regulated microinsurance providers, particularly organizations that primarily serve the poor. In the meantime, commercial insurers would be wise to take advantage of the current situation and develop the expertise to serve the low-income market before they encounter competition from more specialized microinsurers.

\section{Regulatory barriers for distributing microinsurance products}

There are, however, some regulations that do make it more difficult for commercial insurers to provide microinsurance. Commercial companies are unlikely to serve the poor directly, but instead generally offer a product line through alternative distribution mechanisms, such as community organizations, MFIs, retailers and others. However, regulatory barriers can inhibit the use of these distribution channels even though they might be effective in reaching low-income markets.

Many insurance supervisors are not prepared for the emergence of new distribution channels that extend the outreach to low-income households; nor are they ready for the use of new technologies that hold significant promise to enhance efficiencies and lower transaction costs. If insurance companies begin experimenting with innovative delivery channels and technologies, they run the risk of getting too far out ahead of the regulators, who may not appreciate that the insurer is entering uncharted territory. The situation certainly calls for ongoing dialogue so that regulators are kept in the loop as insurers innovate to serve the poor.

Regulators may have to reconsider their conventional wisdom in order to expand the availability of microinsurance, particularly with regard to distribution channels. Distribution is not only limited to sales activities; it encompasses a variety of administrative and intermediation activities necessary to deliver the product to the customer. These functions - including marketing, sales, premium collection, policy and client management, policy administration and claims payment - could potentially 
be conducted by various entities that have a comparative advantage vis-à-vis the lowincome market, but have not typically been licensed by insurance supervisors.

MFIs are a key microinsurance distribution channel because they already engage in financial transactions with the low-income market. However, in some jurisdictions, MFIs - and other institutions that work closely with the poor - cannot distribute insurance without conforming to stringent licensing requirements for agents or brokers. For example, the requirement that an agent has to be a private person may not allow MFIs to sell insurance. The requirement to have specialized staff to sell insurance undermines the efficiencies that are possible by selling insurance through loan officers and tellers. Regulations that require insurance to be sold through advice-based models would also be prohibitively expensive for microinsurance.

Furthermore, the training requirements to become a licensed agent may be excessive given the simplicity of microinsurance products. Should a poor housewife have to go through 100 hours' worth of training to sell US\$500 endowment policies to her neighbours? In some jurisdictions, the licensing requirements for agents are not strictly enforced, allowing MFIs to sell insurance, albeit in a potentially vulnerable legal situation. But do commercial insurers want to take the risk that the supervisor will continue to look the other way? Could insurers and regulators reach an appropriate solution for licensing microinsurance intermediaries?

Restrictions on the amount of agency commission that can be offered by an insurer to the agent may also hinder microinsurance provision. While it is certainly reasonable for regulators to want to prevent high cost structures that will deplete an insurer's life fund, such clauses may create a problem for microinsurers, since the poor are more expensive to serve. This issue opens the door to potential public relations problems for commercial insurers serving the low-income market if they have higher cost ratios for microinsurance, or pay higher commissions to intermediaries serving the poor than the non-poor.

Where microinsurers offer long-term policies, the prescribed commission structure may not be appropriate. For example, where commissions are high in the first year, and then drop off significantly, it creates conditions that encourage overzealous selling, but little effort for retention. This incentive structure is particularly inappropriate when the agent is also responsible for collecting premiums in cash, since the amount of work involved in serving a particular customer does not drop off as much as the incentive does. In such a situation, a high lapse is likely to result, which would undermine the credibility of insurance among the poor.

Another product-related regulatory barrier is the fact that insurance companies cannot underwrite composite business, even though it might be an appropriate product structure for the low-income market. The poor have a variety of riskmanagement needs. Since it is so costly (relative to the premium amount) to serve this market, in some circumstances it may be more efficient to deliver one product that covers multiple perils.

In some jurisdictions, the licensing requirements do not allow the formation of composite insurance companies. The protection achieved by not allowing a commingling of long- and short-term liabilities is relevant for commercial lines of insurance or for policies with large sums insured. However, the same logic does not 
apply to microinsurance, where policies often do not go beyond 5 years terms and the vast majority are for one year or less. Instead, insurers might want to provide bundled products to the low-income market, or at least provide the poor with options to access different covers.

Policy wording requirements are sometimes unsuitable for low-income clients, who are often illiterate - even educated people cannot understand most insurance contracts! Regulations should allow insurance policies for the poor to be written in plain language, without legalese, to ensure that the terms and conditions are easily understood. Commercial insurers, or an industry association, can take the lead in developing user-friendly policy language.

\section{Conclusion}

Insurance is and needs to be a highly regulated industry. Building a risk-management culture is difficult enough - it only takes one or two failed companies to destroy it.

Insurance supervisors are primarily responsible for consumer protection, which comes in two main forms: (1) protecting policyholders in general against insurance company failure; and (2) protecting individual policyholders (or potential policyholders) against unscrupulous sales and unfair policy documents.

There is also a third type of consumer protection - concern for the protection of those who cannot access insurance - which represents the market development function of insurance regulators. The extent to which regulators are willing and able to embrace this development function will have a significant influence on the future scope of microinsurance in their jurisdictions.

The starting point for creating inclusive insurance markets is for supervisors to have a mandate to do so. If insurance supervisors are to comply with this mandate and take their market development responsibilities seriously, they need instructions from policymakers that microinsurance is indeed a priority.

The major challenge for supervisors is to create an enabling environment for outreach and sustainability of the growing microinsurance market. It is quite difficult to provide consumer protection while at the same time encouraging untested, innovative solutions to respond to the insurance needs of low-income households. Adjustments to regulatory frameworks are often perceived as being in conflict with prudential principles and have the risk of creating distortions in the market place. Therefore, supervisors have to find a balance that promotes inclusion - which means extending insurance to the huge low-income market while protecting their investments and confidence - without putting an undue burden on supervisors. This is not an easy task.

Consequently, despite new initiatives to promote inclusive insurance markets, and active discussions in the IAIS and other forums, changes on the ground may take some time in many countries. In those jurisdictions, commercial insurers - which already have the technical expertise, sufficient capital and a license to operate - have an opportunity to get a head start in reaching out to the vast, un-served, low-income market before regulators allow more specialized microinsurance entities to operate.

But to take advantage of this opportunity, commercial insurers will have to overcome some key obstacles. Internally, insurers need to make a commitment to serve the poor, which involves getting to know the market, and having the resources and 
latitude to innovate. In many companies, this "willingness" issue is not an easy one to overcome, at least not until senior executives are convinced that the low-income market is worth the trouble. Externally, insurers have to work hard at securing acceptance by the low-income market about insurance as a relevant risk-management tool, and about the insurer itself.

\section{References}

Botero, F., Churchill, C., McCord, M. and Qureshi, Z. (2006) 'The future of microinsurance', in C. Churchill (ed) Protecting the Poor: A Microinsurance Compendium, Geneva: ILO, pp. 583-601.

Churchill, C. (ed) (2006a) Protecting the Poor: A Microinsurance Compendium, Geneva: ILO.

Churchill, C. (2006b) 'What is insurance for the poor?', in C. Churchill (ed) Protecting the Poor: A Microinsurance Compendium, Geneva: ILO, pp. 12-24.

Genesis Analytics (2005) A Regulatory Review of Formal and Informal Funeral Insurance Markets in South Africa, Johannesburg: FinMark Trust.

McCord, M.J. and Churchill, C. (2005) Delta Life, Bangladesh, CGAP Working Group on Microinsurance, Good and Bad Practices, Case Study No. 7, Geneva: ILO Social Finance Programme.

Prahalad, C.K. (2005) Fortune at the Bottom of the Pyramid: Eradicating Poverty Through Profits, Upper Saddle River, NJ: Wharton School Publishing.

Wiedmaier-Pfister, M. and Chatterjee, A. (2006) 'An enabling environment for microinsurance', in C. Churchill (ed) (2006) Protecting the Poor: A Microinsurance Compendium, Geneva: ILO, pp. 488-507.

\section{About the Author}

Craig Churchill joined the ILO's Social Finance Programme in 2001. He has 15 years of microfinance experience in both developed and developing countries, including Get Ahead Foundation in South Africa, ACCION International, the MicroFinance Network and Calmeadow. In his current position, he focuses primarily on the role of financial services that the poor can use to manage risks and reduce their vulnerability, including microinsurance and emergency loans. He serves as the Chair of the CGAP Working Group on Microinsurance, and on the Editorial Board of the MicroBanking Bulletin. A graduate of Williams College and Clark University, both in Massachusetts, he has authored and edited over 40 articles, papers, monographs and training manuals on various microfinance topics including microinsurance, customer loyalty, organizational development, governance, lending methodologies, and regulation and supervision. 